\title{
Carboxypeptidase-M is regulated by lipids and CSFs in macrophages and dendritic cells and expressed selectively in tissue granulomas and foam cells
}

\author{
loannis Tsakiris ${ }^{1,2}$, Daniel Torocsik ${ }^{3,4}$, Adrienn Gyongyosi ${ }^{3}$, Aniko Dozsa ${ }^{3}$, Istvan Szatmari ${ }^{3}$, Attila Szanto ${ }^{3}$, \\ Gyorgyike Soos ${ }^{1}$, Zoltan Nemes ${ }^{1}$, Laszlo Igali ${ }^{5}$, Ildiko Marton ${ }^{2}$, Zoltan Takats ${ }^{6}$, Laszlo Nagy ${ }^{3}$ and Balazs Dezso ${ }^{1,2,4}$
}

Granulomatous inflammations, characterized by the presence of activated macrophages (MAs) forming epithelioid cell (EPC) clusters, are usually easy to recognize. However, in ambiguous cases the use of a MA marker that expresses selectively in EPCs may be needed. Here, we report that carboxypeptidase-M (CPM), a MA-differentiation marker, is preferentially induced in EPCs of all granuloma types studied, but not in resting MAs. As CPM is not expressed constitutively in MAs, this allows utilization of CPM-immunohistochemistry in diagnostics of minute granuloma detection when dense non-granulomatous MAs are also present. Despite this rule, hardly any detectable CPM was found in advanced/active tubercle caseous disease, albeit in early tuberculosis granuloma, MAs still expressed CPM. Indeed, in vitro both the CPM-protein and -mRNA became downregulated when MAs were infected with live mycobacteria. In vitro, MA-CPM transcript is neither induced remarkably by interferon- $\gamma$, known to cause classical MA activation, nor by IL-4, an alternative MA activator. Instead, CPM is selectively expressed in lipid-laden MAs, including the foam cells of atherosclerotic plaques, xanthomatous lesions and lipid pneumonias. By using serum, rich in lipids, and low-density lipoprotein (LDL) or VLDL, CPM upregulation could be reproduced in vitro in monocyte-derived MAs both at transcriptional and protein levels, and the increase is repressed under lipid-depleted conditions. The microarray analyses support the notion that CPM induction correlates with a robust progressive increase in CPM gene expression during monocyte to MA maturation and dendritic cell (DC) differentiation mediated by granulocyte-MA-colony-stimulating factor + IL-4. M-CSF alone also induced CPM. These results collectively indicate that CPM upregulation in MAs is preferentially associated with increased lipid uptake, and exposure to CSF, features of EPCs, also. Therefore, CPM-immunohistochemistry is useful for granuloma and foam MA detections in tissue sections. Furthermore, the present data offer CPM for the first time to be a novel marker and cellular player in lipid uptake and/or metabolism of MAs by promoting foam cell formation.

Laboratory Investigation (2012) 92, 345-361; doi:10.1038/labinvest.2011.168; published online 12 December 2011

KEYWORDS: carboxypeptidase-M; epithelioid cell; granuloma; lipid-laden macrophage; immunohistochemistry; qRT-PCR

Many intracellular pathogens, persistent or non-degradable particles or antigens may induce helper T-cell-mediated delayed-type hypersensitivity reaction resulting in granuloma formation, a distinct pattern of chronic inflammation. ${ }^{1}$ The morphological diagnostic hallmark of such lesions is the presence of epithelioid cell (EPC) aggregates surrounded by T-lymphocytes. The EPCs correspond to monocyte (Mo)derived tissue macrophages (MA) that became activated by interferon- $\gamma(\mathrm{INF} \gamma)$ of $\mathrm{T}_{\mathrm{H}} 1$ cells and other cytokines to undergo morphological transformation into epithelium-like cell clusters while increasing their phagocytic and antigenpresenting capacities. $^{2-4}$ Among the lesional cells, multinucleate cells may also be seen. Granulomatous inflammation is encountered in special infectious diseases, including tuberculosis, leprosy, brucellosis, toxoplasmosis and catscratch disease. On the other hand, several immune-mediated non-infective granulomatous lesions exist that are induced by unknown or well-defined antigens, as seen in Crohn's disease,

\footnotetext{
${ }^{1}$ Department of Pathology, University of Debrecen, Medical and Health Science Center, Debrecen, Hungary; ${ }^{2}$ Department of Dental Microbiology and Oral Pathology, Dental Faculty, University of Debrecen, Debrecen, Hungary; ${ }^{3}$ Department of Biochemistry and Molecular Biology, University of Debrecen, Medical and Health Science Center, Debrecen, Hungary; ${ }^{4}$ Department of Dermatology, University of Debrecen, Medical and Health Science Center, Debrecen, Hungary; ${ }^{5}$ Department of Cellular Pathology, Norfolk and Norwich University Hospitals, Norwich, UK and ${ }^{6}$ Department of Pediatrics, Semmelweis University, Budapest, Hungary Correspondence: Professor B Dezso, MD, PhD, Department of Pathology, University of Debrecen, Medical and Health Science Center, POB 24, Debrecen 4032, Hungary. E-mail: bdezso@med.unideb.hu
} 
sarcoidosis, primary biliary cirrhosis and in lesions associated with autoimmune conditions, hypersensitive lung and skin diseases. In addition, non-immune-mediated reactions in amyloidosis, lipid accumulation and the presence of foreign particles may also induce granuloma formation. Owing to its ramifying nature, the recognition of the granulomatous pattern of an inflammation in a surgical specimen and the underlying condition is crucial because of the different disease progressions and clinical outcomes, and the treatment protocols may substantially differ from each other. Some of the morphological patterns can easily be recognized using hematoxylin-eosin (H-E), suggestive of the etiology. However, the diagnosis of the granulomatous nature of an inflammation in certain conditions may be difficult on morphological grounds. In some biopsies, only few MAs in clusters are recognized that may suggest a minute granuloma, but the simultaneous presence of nonspecific inflammation, rich in MAs, may obscure the diagnosis. The granuloma may be verified with the use of combined immunohistochemistry (IHC) markers for T cells and MAs. However, they do not provide per se a specific proof for the presence of a granulomatous process, as leukocytes in association with nonspecific inflammations may show similar expression patterns for these IHC markers. To our knowledge, there is presently no antibody in use that could recognize EPCs distinctly on paraffin sections to identify granulomas, selectively.

Based on preliminary IHC staining of paraffin sections, ${ }^{5}$ we found earlier that carboxypeptidase-M (CPM) could be a candidate marker for a selective detection of EPCs to differentiate them from other MA types present in non-granulomatous lesions. ${ }^{5}$

$\mathrm{CPM}$ belongs to the 'regulatory' carboxypeptidase (CP)-N/ E subfamily of zinc-dependent enzymes that includes the adipocyte enhancer-binding protein 1 (AEBP1) located in the nuclei of MAs. ${ }^{6-9} \mathrm{CPM}$ is a cell membrane-bound peptidase with neutral $\mathrm{pH}$ optimum, which metabolizes bioactive peptides, hormones, cytokines and has been found in different cell types, including trophoblasts and alveolar epithelia. ${ }^{10,11}$ Earlier we demonstrated that a portion of lung adenocarcinomas produce CPM, mainly in association with epidermal growth factor recetor (EGFR), and the coexpression resulted in a poor clinical outcome. ${ }^{12} \mathrm{CPM}$ is structurally, catalytically and immunologically distinct from other carboxypeptidases, and expressed on cell membranes in a glycosyl-phosphatidylinositol-anchored form. ${ }^{13} \mathrm{CPM}$ hydrolyses the C-terminal basic arginine or lysine of various peptides, including bradykinin, ${ }^{14}$ anaphylatoxins and the EGF to inactivate them or provide an activating ligand processing for a specific binding to the receptors. ${ }^{6,7,15}$ Previously, CPM has been demonstrated in the MA that is upregulated during Mo-MA differentiation under in vitro conditions. ${ }^{16-18}$ However, CPM has not been systematically analyzed so far in human tissue MAs by means of IHC in a large variety of inflammatory conditions.
This study evaluates the differential expression pattern of CPM in various forms of MAs focusing on EPCs of granulomatous inflammations. Here we demonstrate that CPM is preferentially expressed in EPCs of virtually any type of granulomata, and in lipid-containing tissue MAs, including the foam cells of atherosclerotic plaques and xanthomatous lesions, while other MA types remained negative. Supporting the IHC findings, the in vitro experiments using quantitative real-time RT-PCR (qRT-PCR) and the microarray analyses revealed that the observed acute CPM-mRNA and -protein upregulations correlated with a robust CPM gene activation induced by serum lipids in differentiating MAs or granulocyte-MA-colony-stimulating factor (GM-CSF) + IL-4 in developing dendritic cells (DCs). As EPCs harbor cytoplasmic lipids within a CSF-rich environment, ${ }^{19-26}$ these may explain our finding that CPM-IHC is highly reproducible for the identification of EPC-type MA subpopulations. Therefore, CPM can be nominated as a reliable granuloma and foam cell marker for routine diagnostic purposes.

\section{MATERIALS AND METHODS}

Formalin-fixed paraffin-embedded human tissues were obtained from the archives of the Department of Pathology, University of Debrecen, utilizing protocols approved by the respective institutional review boards. The samples included in this study were all surgical specimens with various forms of inflammations obtained from 246 anonym cases (Supplementary Table S1 and Supplementary Information).

\section{IHC and Immunofluorescent Stainings}

Immune-stainings for CPM were performed on antigenretrieved paraffin sections using monoclonal antibody $(\mathrm{mAB})$ to CPM $(\times 1 / 25$; Novocastra, Newcastle, UK; clone 1C2IgG1), followed by an EnVision ${ }^{+}$-HRP detection (Dako, Glostrup, Denmark) with VIP (purple) or DAB (brown) peroxidase substrates (Vector Labs, Peterborough, UK) as described recently in detail. ${ }^{5,12,27}$ Alternatively, an automated immune-stainer was used (Bond, Leica). For reference, mABs to CD68 (Dako), CD163 (Novocastra) were used with the same method. Immunofluorescent (IF) stainings were made on serial sections of pelleted cells obtained from in vitro experiments, followed by formalin fixation, paraffin embedding. After 1-h incubation with $\mathrm{mAB}$ to CPM, we applied anti-mouse $\operatorname{IgG}(\mathrm{Fab})_{2}$ coupled to polymer-HRP (Dako), and tyramide-TMR (tetramethyl-rhodamine; TSA-TMR System; Perklin-Elmer, USA) as the final (red) fluorochrome. ${ }^{28,29}$ Nuclear counterstaining was made with DAPI (blue fluorescence; Vector Labs). To check the specificity, positive and negative controls were included as published earlier. ${ }^{12}$ IHC for peroxisome proliferator-activated receptor- $\gamma(\operatorname{PPAR} \gamma)$ was carried out on pelleted cells using CSAII detection kit (Dako) as described earlier. ${ }^{28,29}$ 


\section{Laser-Capture Microdissection Isolation of EPCs from Granuloma Tissues}

Cryosections of native lymph nodes harboring sarcoidosis were stained with RNAse-free $\mathrm{H}-\mathrm{E}$ to visualize and locate the epithelioid MA clusters of granulomata. Using serial sections, these were then in situ laser-microdissected and collected from the surrounding cells and tissue compartments (Figure $3 \mathrm{a}_{1}$ and $\mathrm{a}_{2}$ ) using a computer-guided laser-capture microdissection (LCM) microscope (MMI-Olympus LCM system, Glattbrugg, Switzerland). Cellular RNA was then isolated with the use of 'Absolutely Nanoprep RNA' isolation kit (Stratagene) according to the vendor's protocol. The CPMmRNA transcript in EPCs, normalized to cyclophilin-A, was then determined in parallel with reference MA and DC markers (CD86, MCR1, PPAR $\gamma$ ) as described earlier. ${ }^{30-32}$

\section{Monocyte (Mo) Separation}

Human Mo from platelet-free buffy coats were isolated from healthy donors by Ficoll-Hypaque (Pharmacia, Uppsala, Sweden) gradient-centrifugation and immunomagnetic cell separation using anti-CD14-conjugated microbeads (VarioMACS; Miltenyi Biotec, Cologne, Germany) according to the manufacturer's protocols and as described earlier. ${ }^{32,33}$ Cell viability was at least $98 \%$, and Mo purity varied between 95 and $98 \%$. Separated cells were resuspended $\left(1.5 \times 10^{6} / \mathrm{ml}\right)$ in RPMI-1640 supplemented with $10 \%$ heat-inactivated fetal bovine serum (FBS; Invitrogen, Carlsbad, CA, USA) and differentiated into MAs in standard conditions at $37^{\circ} \mathrm{C}$ (Supplementary Information and refs. 32,33). In separate experiments $(n=3)$, reduced FBS or charcoal-stripped serum (CCSS; Sigma) were used for lipid depletion, or supplemented with $20 \mu \mathrm{g} / \mathrm{ml}$ low-density lipoprotein (LDL) in place of $10 \%$ FBS.

\section{Activation of MAs and Early DC Differentiation}

Mo-derived MAs were cultured and differentiated in the presence of the following activating agents added to Mos at the 0 time point $(0 \mathrm{p})$ of cultivation: LDL, oxLDL, VLDL $(20 \mu \mathrm{g} / \mathrm{ml}$; Intracel), and $500 \mathrm{U} / \mathrm{ml}$ GM-CSF or M-CSF, and for the induction of classical and alternative activation pathways: $500 \mathrm{U} / \mathrm{ml}$ interferon- $\gamma$ (IFN $\gamma$ ) or IL-4 (all from Peprotech, London, UK) were added, respectively. Alternatively, MAs were loaded with live (L) or heat-killed (HK) Mycobacterium bovis- bacillus Calmette-Guérin tuberculosis bacilli (TB) (Statens Serum Institut, Copenhagen, Denmark; cell/TB ratio: 1:1) as published earlier ${ }^{34}$ and described in Supplementary Information. HK bacteria were prepared by incubation for $20 \mathrm{~min}$ at $95^{\circ} \mathrm{C}$.

For DC differentiation, following early Mo-MA maturation for $12 \mathrm{~h}$, the cells were cultured with $500 \mathrm{U} / \mathrm{ml} \mathrm{IL}-4+800 \mathrm{U} / \mathrm{ml}$ GM-CSF (Peprotech) for $120 \mathrm{~h}$ as described, ${ }^{35,36}$ or the cytokine cocktail was supplemented with TGF- $\beta$ (Peprotech) in various concentrations. Alternatively, DCs were treated with rosiglitazone (RSG; Alexis Biochemicals) as published previously. ${ }^{36}$ At the indicated time points, cells were collected for paraffin embedding and IF staining, ${ }^{12,28,29}$ or for qRT-PCR. Alternatively, the cultured cell monolayers were stained with Oil-Red-O using standard methods. For combination of the lipid staining with IHC, following CPM-IF staining using FITC fluorochrome, monolayers were treated with $50 \mathrm{ng} / \mathrm{ml}$ Nile-red ${ }^{35}$ (Sigma), washed and counterstained with DAPI.

For FACS analyses, cell stainings were performed using FITC- or PE-conjugated mABs as described earlier. ${ }^{28}$ Labeled ABs for flow cytometry included anti-CD11c-FITC, CD14PE, MHC II-PE and isotype-matched controls (BD Pharmingen, San Diego, CA, USA). The cells were assessed for fluorescence intensity using FACS Calibur cytometer (BD Biosciences). Data analysis was performed using the Cellquest software (BD Biosciences).

\section{Sampling and RNA Isolation}

To obtain total RNA, cells were pelleted at the indicated time points. RNA was isolated with TRIZOL reagent (Invitrogen) according to the manufacturer's protocol. The amount and quality of total RNA was determined by capillary electrophoresis analysis, ${ }^{30}$ using an Agilent 2100 Bioanalyzer (Agilent, Technologies, Santa Clara, CA, USA).

\section{qRT-PCR}

Samples containing equal amounts of RNA $(1 \mu \mathrm{g})$ were used for qRT-PCR. ${ }^{36}$ cDNA syntheses were performed at $42{ }^{\circ} \mathrm{C}$ for $120 \mathrm{~min}$ and $72^{\circ} \mathrm{C}$ for $5 \mathrm{~min}$ using Superscript II reverse transcriptase and Random Primers (Invitrogen) according to the manufacturer's recommendations. The cDNA obtained was used for real-time quantitative PCR (ABI PRISM 7900; Applied Biosystems), 40 cycles of $95^{\circ} \mathrm{C}$ for $10 \mathrm{~s}$ and $60^{\circ} \mathrm{C}$ for $1 \mathrm{~min}$. All PCR reactions were carried out in triplicate with control reactions containing no reverse transcription enzyme. The sequence of the primers and probes used are as follows: CPM $(550+)$ GTCCTCTCTGCAAACCTCCAT, (624-) CCCAGTTGCTTGAACACCAT, $(573+)$ FAM-TGGTGCCC TCGTGGCCAGTT; cyclophilin $(52+)$ ACGGCGAGC CCTTGG, (117-) TTTCTGCTGTCTTTGGGACCT, $(69+)$ FAM-CGCGTCTCCTTTGAGCTGTTTGCA; and PPAR $\gamma$ $(1313+)$ GATGACAGCGACTTGGCAA, (1379-) CTTCAA TGGGCTTCACATTCA and (1322-) FAM-CAAACCTG GGCGGTCTCCACTGAG. Predesigned assays for human CD86 (assay ID: Hs01567025_m1) and human MRC1 (assay ID: Hs00267207_m1), both from Applied Biosystems, were used. The comparative cycle threshold (Ct) method was used to quantify transcripts and normalize to cyclophilin-A expression. ${ }^{36}$

\section{Microarray Analysis}

RNA isolation and the labeling were performed as published in detail earlier. ${ }^{29,33,37}$ Briefly, total RNA was isolated as described above and further purified by using the RNeasy total RNA isolation kit (Qiagen). cRNA was generated from $5 \mu \mathrm{g}$ of total RNA using the SuperScript Choice kit 



Figure 1 Carboxypeptidase-M (CPM) is selectively expressed in epithelioid cells (EPCs) of common lung granulomatous diseases. Identical microscopic fields of granulomatous lung lesions are shown for comparative macrophage-labeling patterns with the use of anti-CPM (right panel) and common macrophage-immunohistochemistry (MA-IHC) reference markers (middle). The disease types are indicated on the hematoxylin-eosin (H-E)-stained photographs (left). (a) The EPCs of sarcoidosis are distinctly labeled with CPM, including the multinucleate cell (arrow). The staining pattern is similar with CD68, although the latter decorates additional non-granulomatous macrophages (arrowheads). (b) Granuloma (arrows) obtained from early active tuberculosis shows CPM expression, including the multinucleate macrophages (encircled) and the labeling is restricted to EPCs, as opposed to pan-macrophage marker CD163, which stains other macrophages as well (middle panel, arrowheads and lower-right), (c) In contrast, palisade epithelioid cells of advanced tuberculosis, which are labeled intensively with CD68, are basically negative for CPM. Note that some of the multinucleate cells, however, still express CPM (slim arrows), but others are nearly non-reactive (thick arrows). IHC stainings for a were visualized with VIP (purple), and for $\mathbf{b}$ and $\mathbf{c}$ with diaminobenzidine (DAB) (brown) peroxidase chromogenic substrates, respectively. Nuclear counterstains are methyl green or hematoxylin. 

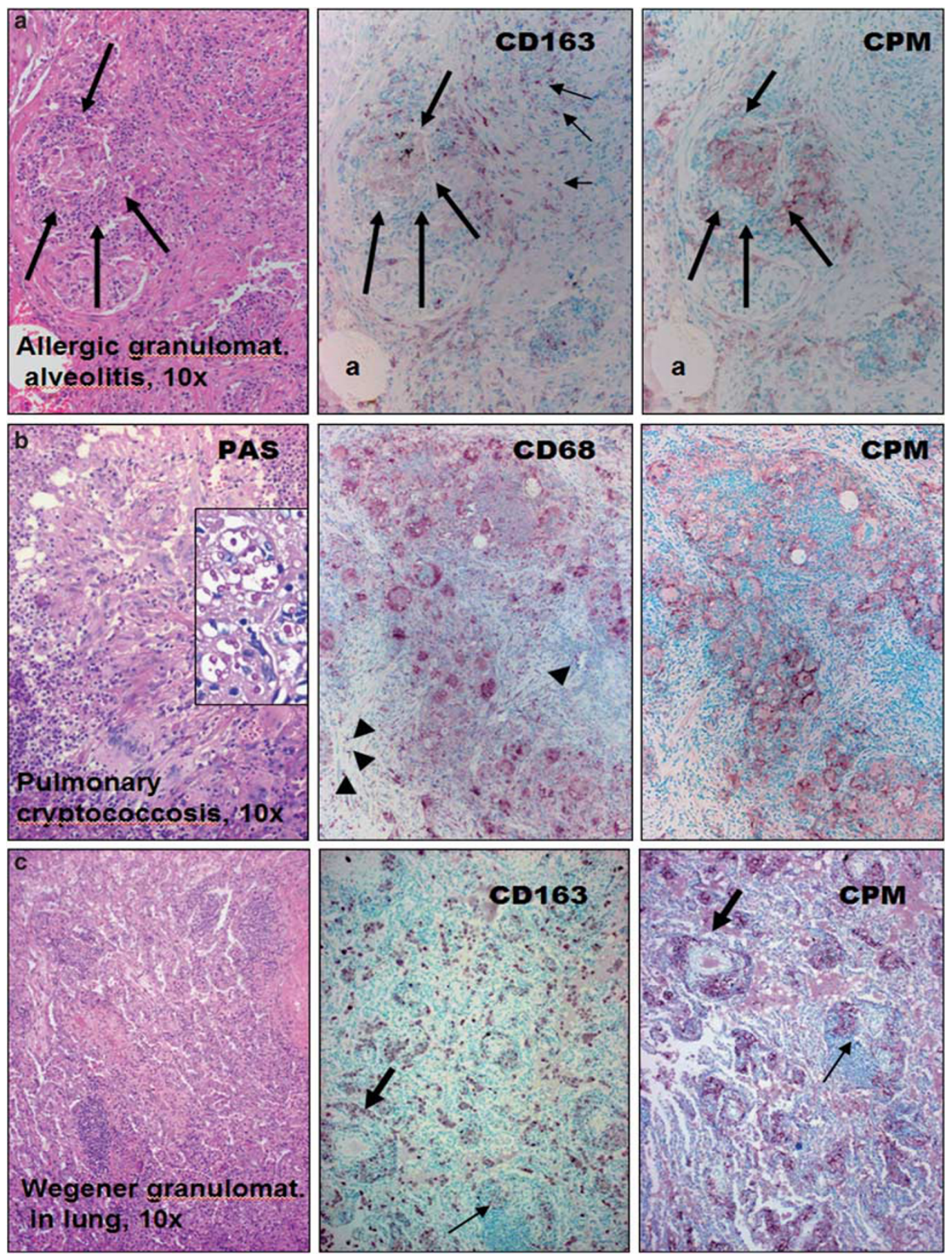

Figure 2 Granuloma macrophages invariably express carboxypeptidase-M (CPM) in uncommon lung disorders. (a) In allergic granulomatous alveolitis, the lesional cells (between thick arrows) are labeled more distinctly with CPM than CD163. As shown the same microscopic field (indicated by the same alveolus: a), CD163 decorates non-epithelioid reactive macrophages, also (slim arrows) which are negative for CPM. (b) Identical microscopic field of pulmonary cryptococcosis shows CPM positivity mainly in epithelioid cells (EPCs), as opposed to CD68, which decorates many more macrophages (arrowheads). Inset demonstrates the PAS-positive cryptococci with high magnification. (c) Wegener granulomatosis (vasculitis): as compared to the identical necrotizing inflamed vessels (indicated by the thick and slim arrows) and other compartments on serial sections, there is more prominent CPM staining in macrophages, mainly at sites of tissue damage (the fine cellular detail of the same image in higher magnification is seen in Supplementary Figure S2).

(Invitrogen) and the High Yield RNA transcript labeling kit (Enzo Diagnostics). Fragmented cRNA was hybridized to Affymetrix (Santa Clara, CA, USA) arrays (HU133 Plus 2.0) according to Affymetrix standard protocols. Analysis was performed using the GeneSpring7.2 (Agilent Technologies) software. 


\section{Statistical Analysis}

Methods for statistical analyses of qRT-PCR are described in Supplementary Information.

\section{RESULTS \\ Positive CPM Expressions in Tissues Exhibiting Granulomatous Inflammations}

We examined tissue sections with inflammatory MAs obtained from over 240 cases to check the presence of CPM (Supplementary Table S1). Resting MAs of normal tissues and MAs in inflammations with no significant tissue damage show no or low levels for CPM staining (Supplementary Figure S1). However, EPCs of all cases with sarcoidosis $(n=48$; Figure 1a), early active tuberculosis $(n=4$; Figure $1 b)$, other pulmonary granulomatosis including Wegener vasculitis (Figure 2a-c and Supplementary Figure S2), and cat-scratch disease, toxoplasmosis and tumor-associated epithelioid lymphadenitis (Figure 3a-d) constantly expressed CPM, mainly in membrane-bound form. The CPM expression levels, however, decreased remarkably in palisade epithelioid MAs that are related to advanced caseous-necrotic granulomas of active tuberculosis (Figure 1c). This appears to be a tuberculosis-specific phenomenon because other granuloma types with necrosis, for example, cat-scratch disease (Figure $3 \mathrm{~b}$ ) and granulomatous panniculitis (Figure 4c), do exhibit palisading EPCs, but with CPM expression. On the other hand, the staining was found not only in mononuclear EPCs but also in multinucleated MAs (Figure 1a and b). Based on qRT-PCR analyses, the laser-microdissected EPCs of sarcoidosis granuloma tissues $(n=3)$ exhibited high CPMmRNA transcript levels, as compared to reference MA and DC markers (MRC1, CD86, PPAR $\gamma$ ), suggesting active CPM synthesis with increased protein expression (Figure $3 a_{1}-a_{3}$ ). Furthermore, CPM expression was seen in non-immune granulomas, including granulomatous amyloidosis (amyloidoma) and foreign body giant-cell reactions (Figure 4a and b). When minute granulomata are present admixed with other inflammatory (non-granulomatous) MAs, as seen in certain cases of Crohn's disease, CPM reliably 'picks up' the lesional EPCs from tissues to allow establishing adequate diagnosis (Figure $4 \mathrm{~d}$, right pictures). In addition, we found CPM-positive MAs in subcutaneous gouty tophus and rheumatoid nodules with various expression levels (not shown). According to the comparative immune-staining using common reference MA markers, anti-CPM appears to label EPCs selectively from the rest of other MAs that were invariably stained with CD68, CD163 in tissues (Figures 1-4). Previously, we and others showed that, in addition to CD68, CD163, tissue granuloma MAs may express CD14, CD11c and HLA-DR, which reflect that these activated cells in part exhibit both MA and DC phenotypes. ${ }^{38-42}$

Based on the demonstrated cases, except for the advanced tuberculosis, one can conclude so far that CPM is consistently expressed in granuloma MAs, regardless of immune or non-immune nature and tissue type. Therefore, CPM appears to be a useful single IHC marker for the recognition of any granuloma. As CPM was found to be absent in other MA types including the resting and reactive cells, CPM expression in EPCs should be an induced phenomenon when EPCs are formed, as an acquired feature. Consequently, CPM is not present constitutively in any tissue MAs, but it is induced in distinct epithelioid-MA subpopulation(s), likely to serve enzymatic function(s) during the course of granulomatous inflammation.

\section{MA-CPM-Protein and -mRNA Inductions with MA-Activating Agents}

The above morphological findings on human tissues with granulomatous inflammations prompted us to check whether IFN $\gamma$ could be the proximate CPM inducer in such lesions. This is not unreasonable to assume because IFN $\gamma$ of the $\mathrm{T}_{\mathrm{H}} 1$ $\mathrm{T}$ cells is known to account for the classical MA activation to become 'transformed' into EPCs in immune-mediated granulomatous lesions. ${ }^{1,2,25}$ Therefore, we activated in vitro normal human Mo-derived MAs with IFN $\gamma$, and IL-4 (classical and alternative MA activation pathways) or CSFs. Furthermore, as fully developed tuberculosis showed a strikingly decreased CPM expression of EPCs (Figure 1c), an additional MA group was included where cells were infected with TB. The treated cells of different groups were then collected for sectioning and IF staining, or used for synchronous qRT-PCR analyses to measure CPM-mRNA levels. Earlier, we and others demonstrated that during culturing of Mos in the presence of $10 \%$ FBS, cells spontaneously differentiated into MAs, while cytokine treatments may activate MAs or differentiate into DCs. ${ }^{30,32,33,36}$ As shown in the

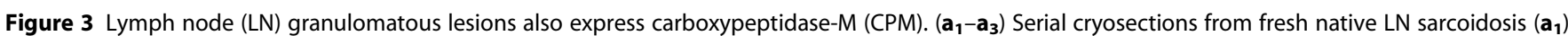
were used for in situ laser microdissection of epithelioid cells (EPCs) from rest of the inflammatory cells (holes in $\mathbf{a}_{\mathbf{2}}$ represent the arrow-indicated EPC clusters of $\mathbf{a}_{\mathbf{1}}$ after removal). The EPCs $(n=3)$ were than collected and analyzed for CPM-mRNA in the function of reference markers using quantitative real-time reverse transcription-polymerase chain reaction (qRT-PCR) analyses $\left(\mathbf{a}_{\mathbf{3}}\right)$. Normalized to cyclophilin, CPM transcript is found the most prominent in EPCs compared with CD86, MRC1, and PPAR $\gamma$ macrophage and dendritic cell markers. Inset shows the positive immune-staining for CPM-protein in EPCs obtained from the same specimen. (b and c) Granulomatous lymphadenitis exhibiting positive staining for CPM in EPCs. Note that cat-scratch disease (b) shows suppurative necrosis (black asterisk), and arrows point to palisade EPCs with CPM positivities (light purple cells). In toxoplasmosis (c), CPM ${ }^{+}$ EPCs are obvious (purple cells). (d) As shown in tumor-associated reactive lymphadenitis, epithelioid cells selectively express CPM, as opposed to CD68 labeling. Note that the small framed regions representing the same microscopic field shows more prominent CPM staining compared with CD68 image (lower right, digitally magnified). 
IF photographs (Figure 5), Mos do not express CPM-protein in detectable amounts; however, during the early phase of Mo-MA transition, without any activating agents, cells start producing CPM at protein levels that culminate in detectable amounts by $12-72 \mathrm{~h}$ of culture (Figure $5 \mathrm{c}$ and $\mathrm{d}$ ). This indicates that an induced CPM-protein upregulation occurs

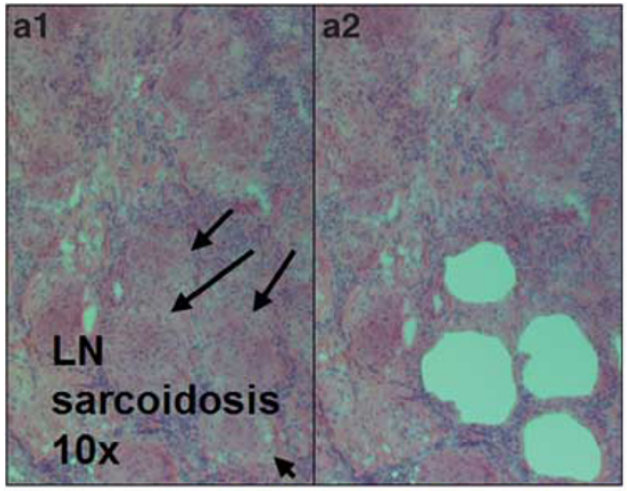

\section{a3 CPM-mRNA of microdissected EPCs from LN sarcoidosis}
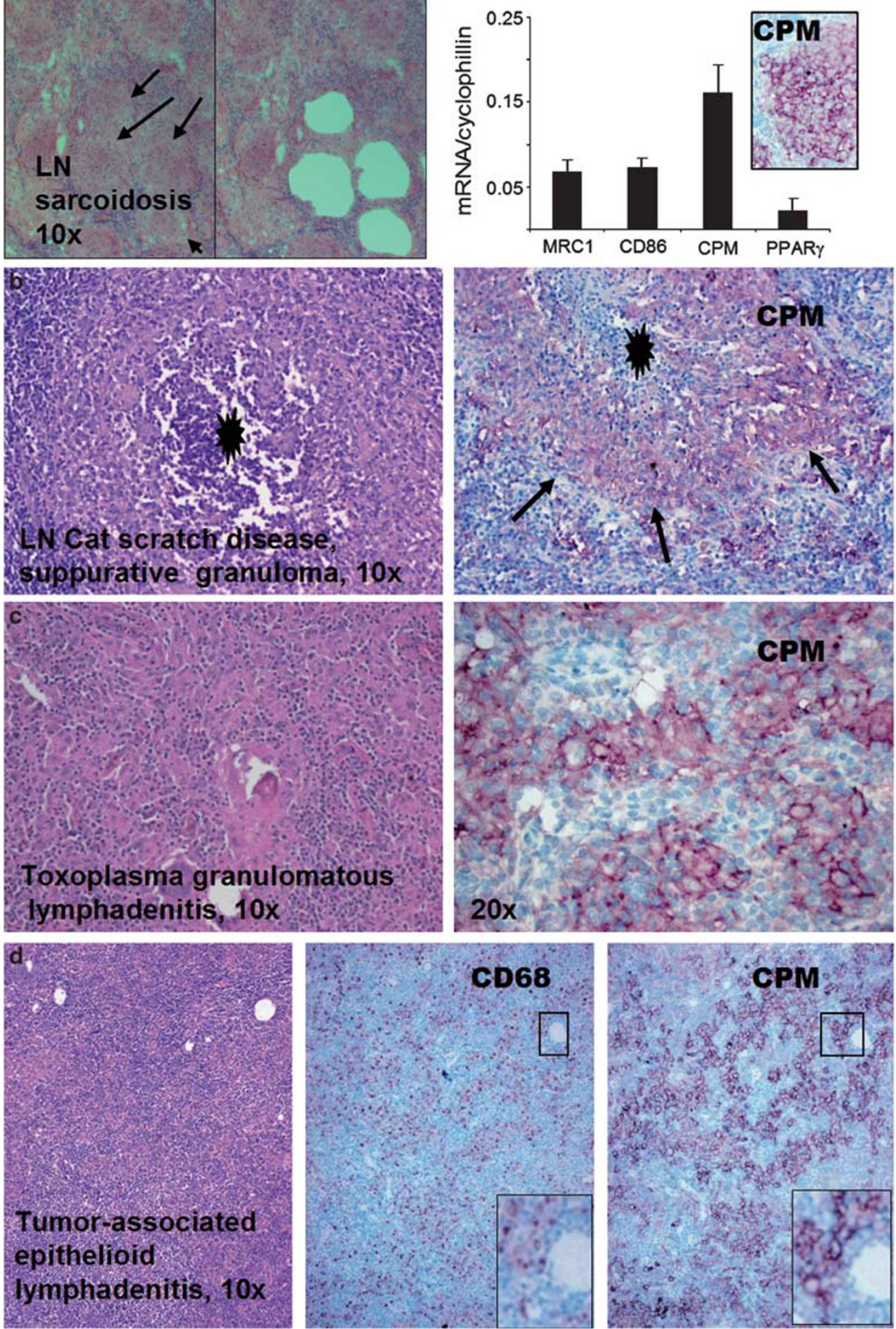

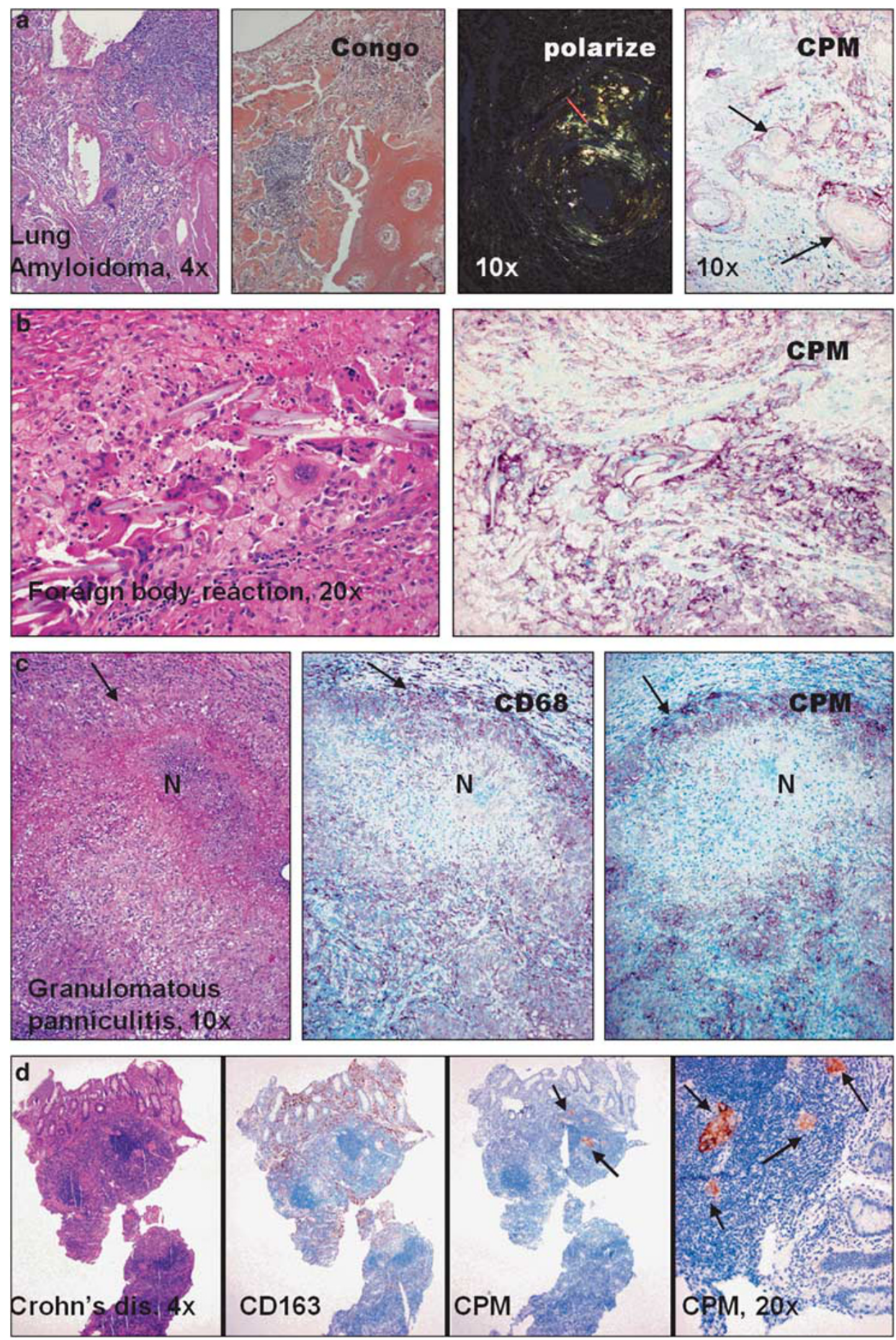

Figure 4 Non-immune-mediated granuloma cells also express carboxypeptidase-M (CPM). (a and b) Besides epithelioid macrophages, foreign body giant cells (arrows) of lung amyliodoma (a) and surgical suture-associated multinucleate macrophages (b) show CPM expression (purple cells). (c) Palisade epithelioid cells (EPCs) of granulomatous necrotizing (N) panniculitis always express CPM. Arrows indicate positively labeled epithelioid cells (purple). (d) As shown in the present intestinal biopsy specimen harboring Crohn's disease, CPM-immunohistochemistry (IHC) readily and reliably 'picks up' the lesional granuloma macrophage clusters (arrows, brown cells) from the rest of CD163 ${ }^{+}$non-granulomatous macrophages.

during Mo-MA differentiation, in concert with previous publication, ${ }^{17,18}$ and the levels remain elevated throughout the culture time. As judged under the fluorescence microscope, the CPM-protein expression levels appeared to be increased in the presence of IFN $\gamma$ and IL-4 (Figure 5e and f), but the corresponding CPM-mRNA levels did not show 

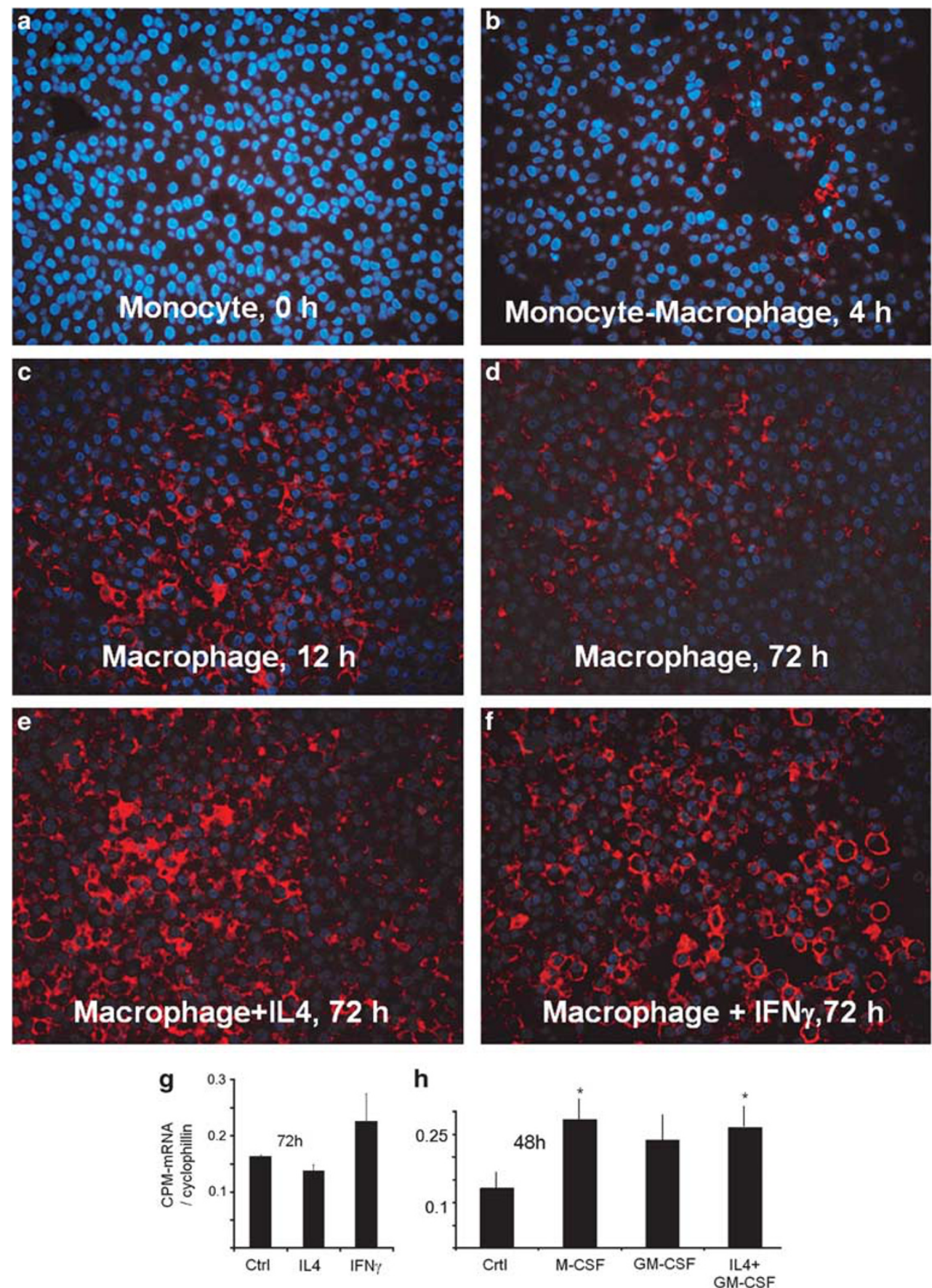

Figure 5 In vitro carboxypeptidase-M (CPM) expression during monocyte-macrophage (Mo-MA) differentiation and in response to activating cytokines. (a-f) CPM-immunofluorescence (IF) of paraffin-embedded sections obtained from cell cultures during Mo-MA differentiation in the presence or absence of activating cytokines. As demonstrated, monocytes do not express CPM. Differentiating macrophages, however, start expressing CPM, which is culminated at 12th hour (c, red fluorescence) and remains elevated during the culture time (d). Although, interleukin-4 (IL-4) and interferon- $\gamma$ (INF $\gamma$ ) apparently increases the CPM-protein expression levels (e and $\mathbf{f}$ ), the corresponding CPM-mRNA $(n=3)$, normalized to cyclophilin, showed no significant upregulation in Mo-derived MAs during the 72-h stimuli (g). In contrast, separate experiments showed that CPM transcripts of macrophages are significantly increased at the $48^{\text {th }}$ hour of culture time in the presence of macrophage-colony-stimulating factor (M-CSF) and IL-4 + granulocytemacrophage-colony-stimulating factor (GM-CSF) $(*)$, the latter representing cells under maturation toward dendritic cells (h). Original magnifications for IF images: $\times 40$; the nuclear counterstain is 4'-6-diamidino-2-phenylindole (DAPI) (blue fluorescence).

significant further increase in IFN $\gamma$-treated MAs as compared to non-treated cells (Figure $5 \mathrm{~g}$ ). However, M-CSF and IL-4 + GM-CSF (leading to DC differentiation) could induce significant CPM-mRNA transcripts at $48 \mathrm{~h}$ (Figure $5 \mathrm{~h}$ ), but the increase returned to a nonsignificant value for M-CSF by the end of culture time (not shown). Figure 6a demonstrates 

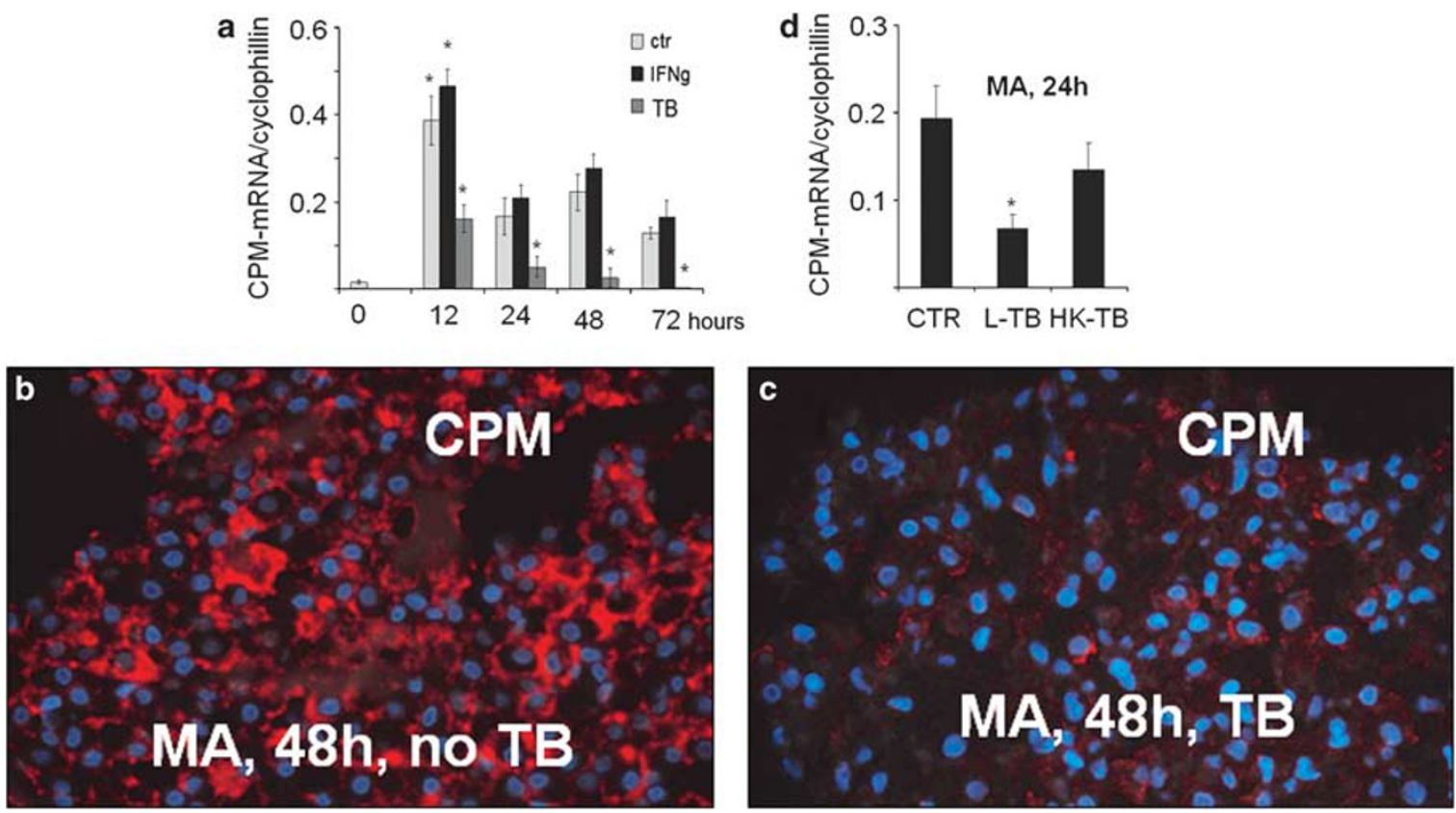

Figure 6 Live but not dead mycobacteria downregulate carboxypeptidase-M (CPM) transcript and protein in macrophages (MAs). (a) mRNA levels of CPM during in vitro differentiation of monocytes into MAs are shown in the presence of interferon- $\gamma$ (IFN $\gamma$ ) or Mycobacterium bovis-bacillus CalmetteGuérin (BCG) tuberculosis bacilli (TB) at various time points. As shown, control samples at $12 \mathrm{~h}$ vs 0 time point and TB-treated vs control (non-infected) samples at all the indicated time points were found significant. (b and $\mathbf{c}$ ) The immunofluorescence (IF)-stained macrophages revealed striking downregulation in CPM-protein expression by the 48th hour of culture when infected with TB (c) compared to control (non-infected) macrophages expressing CPM (b, red fluorescence). (d) In separate experiments $(n=3)$, cells were harvested at $24 \mathrm{~h}$ after treatment with live (L) or heat-killed (HK) TB bacilli followed by a reverse transcription-polymerase chain reaction (RT-PCR) analysis for CPM-RNA expression. As shown in this figure, significant CPM-mRNA downregulation occurred only in MAs that were infected with live TB, but no remarkable decrease in transcript was found when HK bacilli were used, suggesting that CPM downregulation is likely dependent on the viability of mycobacterium. All PCR data shown in panel a and panel $\mathbf{d}$ are expressed as a ratio of the CPM transcript relative to cyclophilin expression. Error bars indicate the s.d. of the relative expression. ${ }^{\star}$ Significant $(P<0.05)$ compared with the respective control value.

the timescale for CPM-mRNA levels, comparable to IF findings. Remarkably, there was a significant increase in CPM-mRNA at the 12th-hour time point of culture in differentiating MAs compared with Mo-mRNA levels (Figure 6a, light gray columns), indicating a rapid synthesis of CPM during Mo-MA transition. In addition, this figure draws attention to an interesting phenomenon, indicated earlier by the IHC (Figure 1c): the presence of TB markedly and gradually downregulates CPM-mRNA of infected MAs (Figure 6a, dark gray columns). By the 72nd hour of culture and in the presence of bacilli, basically no CPM transcript was found in infected MAs and the inhibition of CPMmRNA proved to be significant compared with non-infected cells at each time point, even though that $25 \%$ of the infected cells died out by the end of the experiment. The IF findings demonstrated the same phenomenon at protein levels, as CPM-peptide nearly disappeared by the 48th hour of culture time (Figure 6c), while the TB-free (control) MAs preserved the normal upregulated CPM expression level (Figure 6b). When, however, heat-inactivated killed bacilli were used (HK-TB), only mild decreases in CPM transcript and protein levels occurred (Figure 6d), indicating that only live mycobacteria are capable of downregulating MA-CPM significantly. On the other hand, live TB-infected MAs upregulate CD14 and CD11c, but not HLA-DR (Supplementary Figure S3), consistent with previous publications. ${ }^{21,39,40}$

TGF- $\beta$, which is known to be regulated in DCs, ${ }^{41}$ did not change the CPM expression pattern of both differentiating MAs and DCs and no alteration was found in HLA-DR expression (Supplementary Figure S4).

\section{CPM Expression in Lipid-Laden Tissue MAs}

During the tissue screening for CPM-protein using IHC, we found that lipid-laden MAs also consistently express fair amounts of CPM-protein that can be detected as easily as in granuloma-EPCs. Remarkably, foam MAs of gallbladder cholesterolosis, early atherosclerotic plaques and xanthomatous lesions always express CPM (Figure $7 \mathrm{a}-\mathrm{c}$ ), unless these cells became senescent or degenerated (not shown). Moreover, a robust CPM expression is seen in MAs of type-I Gaucher's disease (Figure 8a), a genetic defect of cerebrosidase. ${ }^{43}$ This enzyme deficiency results in excess amounts of unprocessed glycolipids in phagocytes that become lipid-laden 'Gaucher's cells' and accumulate in lymphoid tissues and spleen. ${ }^{44}$ Similarly to this finding, intense CPM expression is recognized in lipid pneumonias 

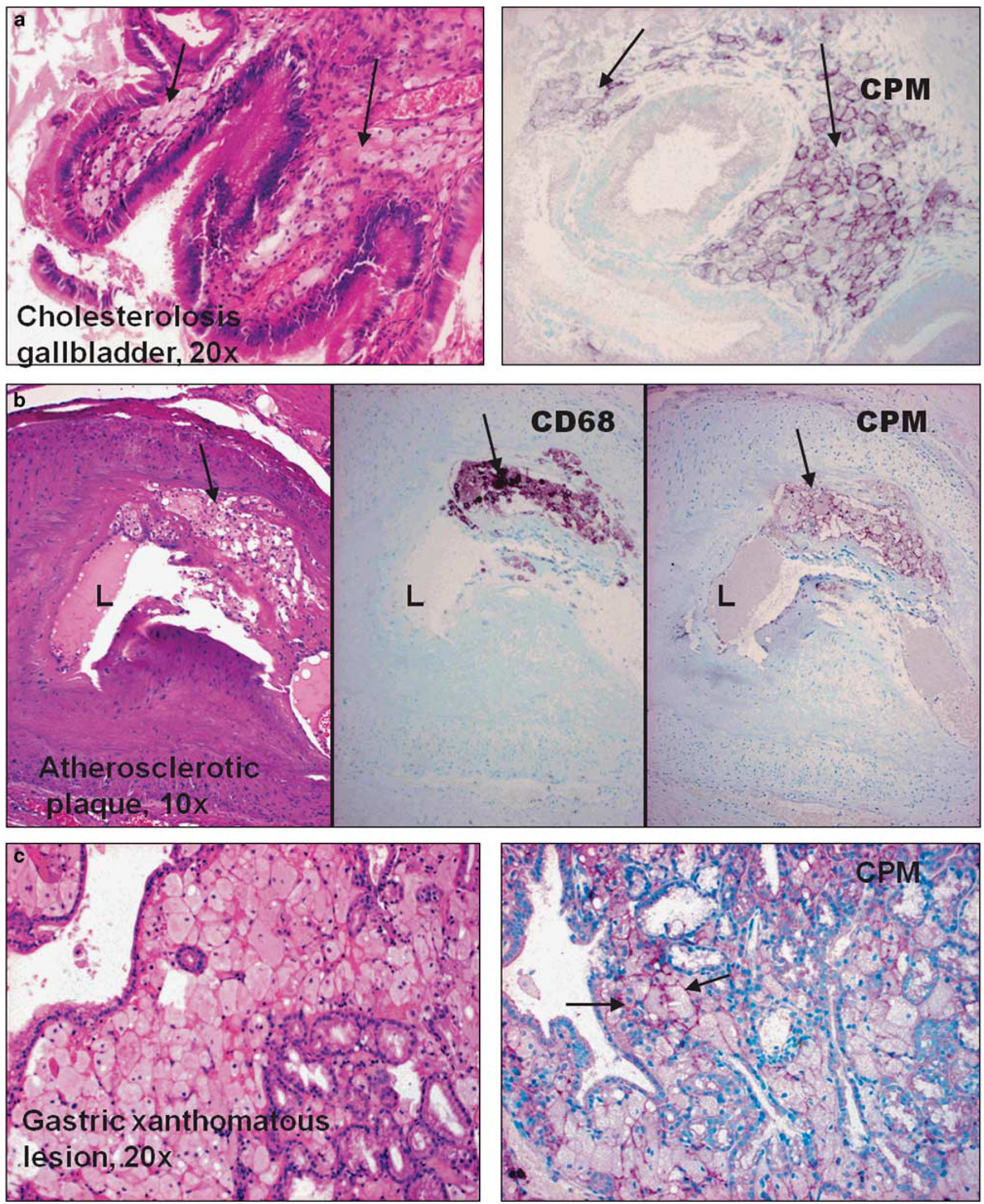

Figure 7 Cholesterol-laden tissue macrophages always express carboxypeptidase-M (CPM). (a-c) CPM expressions by xanthomatous tissue macrophages (arrows) are demonstrated in various lesions, including cholesterolosis (a) and gastric mucosa xanthoma (c). As shown in the serial sections of an early atherosclerotic plaque (b), foam macrophages are distinctly labeled by CPM, comparable with CD68 pattern (arrows). 

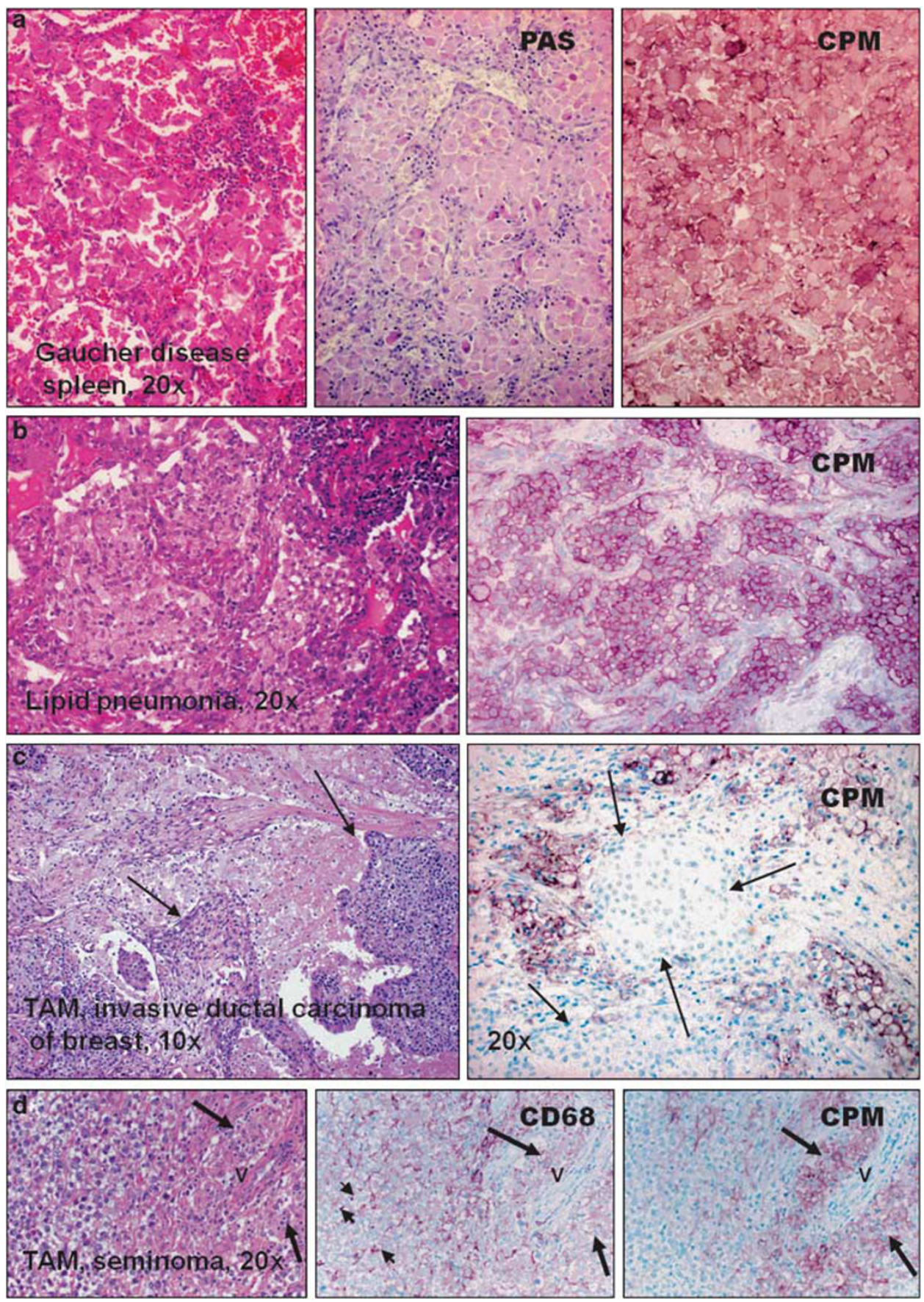

Figure 8 Carboxypeptidase-M (CPM) ${ }^{+}$foam cell accumulation in various pathological disorders. (a) Type- 1 Gaucher disease, a genetic defect of cerebrosidase results in a lipid-laden macrophage accumulation, which expresses remarkably large amounts of CPM-protein, probably in association with glycolipid uptake. (b) Lipid pneumonia is characterized by the accumulation of foam macrophages, which constantly express CPM along the cell membrane (cells with purple cytoplasmic membrane). (c and d) Tumor-associated macrophages (TAM) express CPM when related to significant cell destruction, and in turn lipid uptake occurs by the phagocytes. Arrows in images $\mathbf{c}$ exhibiting breast cancer point to live neoplastic cell nests surrounded by CPM ${ }^{+}$ macrophages (MAs). (d) The same microscopic filed of classic testicular seminoma obtained from serial sections ( $\mathbf{v}$ indications are for the same vessel): note that epithelioid TAMs (long arrows) are strongly positive for CPM; as opposed, CD68 also labels other macrophage types with no epithelioid cell (EPC) morphology (short arrows).

(Figure 8b) and tumor-associated MAs when related to tissue damage, and in turn lipid uptake takes place (Figure 8c and d). Lipid granulomas always show CPM positivity (not shown).

\section{Serum- and Lipid-Supplemented MAs have Enhanced CPM Expression}

The CPM-IHC results on lipid-laden tissue MAs guided us to perform additional in vitro experiments. Following a 
transient 4-h culture of cells in 2\% FBS to allow adherence, Mo-derived early MAs were then further maintained in FBS-deprived culture medium $(0.5 \% \mathrm{FBS})$ or they were cultured in medium containing 10\% FBS (control MAs), or supplemented with oxLDL, LDL or VLDL. As shown Figure 9a, CPM-mRNA expression of LDL-supplemented MAs exhibited an enhanced upregulation as compared with values of cells kept in 10\% FBS alone. Not surprisingly, the $\mathrm{CPM}$-protein was found also upregulated in differentiating MAs in the presence of 10\% FBS (control MAs; Figure 9c) while displaying cytoplasmic lipid droplets, as opposed to low CPM-protein expression level of MAs, which were kept in $0.5 \%$ FBS (Figure 9b). Furthermore, MAs in CCSS, representing lipid-depleted condition, express decreased CPM, while adding LDL to CCSS the lipid alone enhanced the CPM transcript expression levels (Figure 9d). HDL and oxLDL did not affect CPM expression pattern, but VLDL could enhance CPM, comparable with LDL (not shown). The combined mRNA and protein data, therefore, serve as in vitro evidence that LDL is one of the lipids that prominently orchestrates the upstream CPM regulation during the early phases of MA differentiation. Based on flow cytometry analysis, neither CCSS nor LDL altered CD14 and CD11c expression patterns on differentiating MAs (Supplementary Figure S5). In further support of the lipid-signaling pathway, when $\operatorname{PPAR} \gamma$ (a lipid-regulated nuclear receptor) of DCs was induced using a potent PPAR $\gamma$-activating agent RSG to decrease intracytoplasmic lipids (as demonstrated earlier by us and others ${ }^{45,46}$ ), the CPM-protein level became remarkably decreased in these cells, as judged by comparative immunoperoxidase labeling (Supplementary Figure S6).
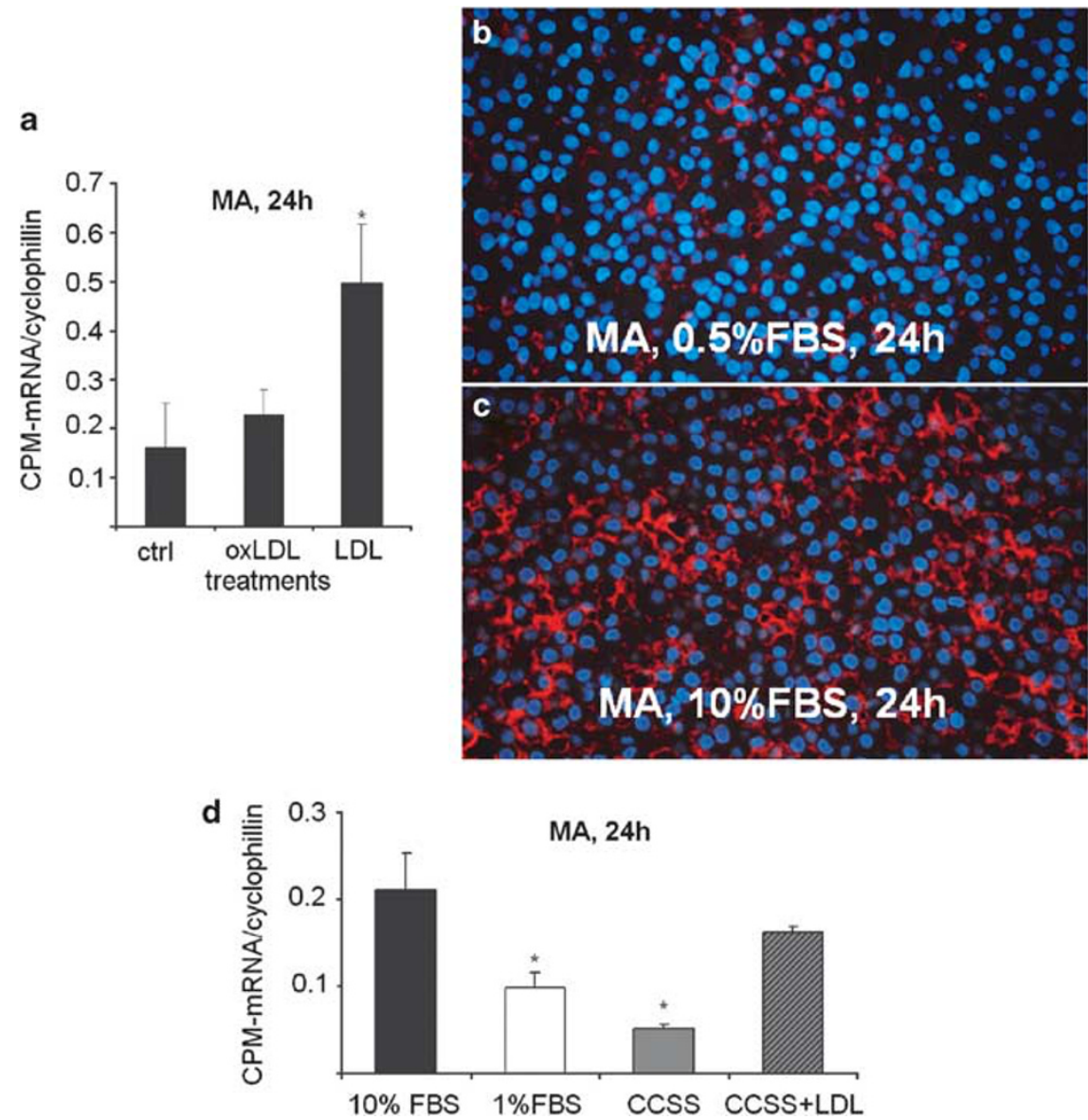

Figure 9 Carboxypeptidase-M (CPM) upregulation is mediated by lipids including low-density lipoprotein (LDL). (a) mRNA levels of CPM in differentiating macrophages (MAs) after 24-h treatments with LDL or oxidized LDL (oxLDL). Data $(n=3)$ are plotted as ratios of the transcripts relative to cyclophilin expression. Error bars indicate the s.d. of the relative expression. ${ }^{\star} P<0.03$, compared with the respective control value of cells kept in $10 \%$ fetal bovine serum (FBS), only. As shown, supplementation of $10 \%$ FBS with LDL, but not oxLDL, resulted in a significant CPM upregulation. (b-c) IF-stained MAs show no upregulation in CPM-protein expression when serum-depleted (0.5\% FBS) culture medium is used (b), as opposed to normal elevated CPM level in cells (red fluorescence) kept in 10\% FBS-containing medium (c). (d) In separate experiments $(n=3)$ using cells obtained from other donors, MAs were maintained in either $1 \%$ FBS or charcoal-stripped serum (CCSS) for $24 \mathrm{~h}$, instead of $10 \%$ FBS (control). As indicated in this figure, the CPM transcript remained significantly downrepresented $\left({ }^{*}<0.05\right)$ in both cases; however, when CCSS was supplemented with $20 \mu \mathrm{g} / \mathrm{ml} \mathrm{LDL}$, the CPM upregulation return to high levels, comparable with differentiating control cells kept in 10\% FBS. Original magnification for immunofluorescence (IF) images with $4^{\prime}$-6-diamidino-2phenylindole (DAPI) nuclear counterstain (blue): $\times 40$. 


\section{GM-CSF-Mediated CPM Gene Activation during Early DC Differentiation}

When MAs were maintained in 10\% FBS for $12 \mathrm{~h}$ followed by a 5 -day culture in the presence of IL- $4+$ GM-CSF to induce DC differentiation, there was a remarkable increase in CPM-mRNA and concomitant protein upregulations. The corresponding microarray data show that following an acute CPM-gene upregulation during Mo-MA differentiation, primarily associated with lipid uptake from FBS (Figure 10a and $c$ ), there is a further increase in CPM gene activation during the early MA-DC transformation; the latter is mediated by the cytokines IL-4 + GM-CSF (Figure 10b). Importantly, during the early DC differentiation, the immature cells, displaying antigen-presenting morphology, still harbor cytoplasmic lipid, although the quantity appears to be lower compared with early MA-lipid contents at $12 \mathrm{~h}$ (Figure 10c versus $\mathrm{d}$ ). On the other hand, CPM-protein remained elevated in DCs by the end of culture time (Figure 10e). By using a combined novel in situ IF staining on monolayers for the simultaneous detection of CPM (visualized with FITC) and lipids (applying the red fluorescent Nile-red), it is obvious that the two cellular components are indeed co-present synchronously in DCs (Figure 10f).

\section{DISCUSSION}

The phenotypically and functionally versatile MAs are major participants in inflammations, lipid metabolism, immunity and tissue remodeling via phagocytic, antigen-presenting and cytokine-producing capacities. ${ }^{47,48}$ This study has generated compelling evidence for the first time that by using a single CPM-IHC, the morphologically distinct MA subpopulations, the EPCs of granulomatous inflammations and the foam cells can be selectively identified with high specificity and acceptable sensitivity from the rest of tissue MAs in paraffin sections. Therefore, CPM appears to be a reliable marker when there is a need to confirm the presence of minute granuloma in a biopsy specimen or in tissues not unambiguous for granulomatous or xanthomatous lesions. This is based on the consistent IHC finding that CPM in resting MAs is not present constitutively at detectable amounts; instead, CPM-protein expression is induced exclusively in EPCs along with the transcript as confirmed by qRT-PCR analyses of the microdissected tissue granuloma MAs.

In vitro, CPM upregulation could be reproduced under two conditions: (i) in association with lipid environment during Mo-MA differentiation, and (ii) in response to M-CSF and IL-4 + GM-CSF, resulting in DC transformation. Both the fatty-changed EPCs and the CSF microenvironment have been described in granuloma MAs, ${ }^{21,26,34}$ providing a rational explanation for the consistent CPM positivities on tissue sections. Despite the selective expression of CPM in granuloma EPCs, indicating IFN $\gamma$ effect, ${ }^{1}$ the present in vitro experiments ruled out a dominant role of either IFN $\gamma$ or IL-4 alone (common MA activators) as possible upstream CPM regulators at transcriptional levels. On the other hand, the observed CSF-induced CPM expression reflects previous data that CPM of bone marrow's mononuclear hematopoietic cells is upregulated in the presence of CSF. ${ }^{49}$

The interesting finding that live but not dead mycobacteria downregulate CPM in infected MAs is likely to be associated with the intracellular virulence of the organism. The molecular mechanism of mycobacteria-mediated CPM inhibition is unclear yet and this issue was beyond the scope of this study, but will warrant further research. Nevertheless, we earlier documented that live mycobacteria can activate PPAR $\gamma$ to decrease the intracytoplasmic lipid droplets of infected MAs, ${ }^{34}$ and as demonstrated in this study, RSGactivated PPAR $\gamma$ upregulation of DCs, resulting in lipid efflux, comes with a substantially decreased MA-CPM-protein expression (Supplementary Figure S6), an observation that may serve as a preliminary and hypothetical explanation.

The in vitro lipid-induced upstream CPM expression, which could be further enhanced with LDL or VLDL, correlates with the IHC finding that foam MAs do consistently exhibit CPM at tissue levels. The present observation confirms previous results, which demonstrated that CPM is an MA-differentiation marker, ${ }^{16-18}$ but the CPM upstream expression is primarily associated with lipid uptake by MAs during maturation. On the other hand, our microarray results have shown that during MA-DC transition, a robust upstream CPM expression develops at both transcriptional and protein levels, while cells keep exhibiting cytoplasmic lipids. As opposed, when the lipid-regulated transcription factor PPAR $\gamma$ of DCs was activated by RSG to decrease intracytoplasmic lipids, ${ }^{46}$ the CPM-protein expression became downregulated. Taken together, these phenomena are consistent with the recent GeneChip-based genome-wide expression microarray data, which demonstrated that during the transition of MAs into DCs, the acutely upregulated genes were associated with lipid metabolism, which in turn may modify and activate genes primarily involved in immune functions. ${ }^{33}$ These data correlate with the recent publication that resident intimal DCs accumulate lipids and contribute to the initiation of atherosclerosis, ${ }^{50}$ that is, foam cells in plaque, which we have now revealed to be positive for CPM (Figure $7 \mathrm{~b}$ ). These data and the present IHC findings on tissues all make it reasonable to speculate that in certain tissue microenvironments, notably necrosis, lipid-rich atheromatous plaques of arteries with inflammatory MAs actively upregulate CPM; this is possibly for an enzymatic action on proinflammatory peptide(s) involved in cell signaling for lipid metabolism ${ }^{51,52}$ to scavenge unwanted lipids at tissue sites, which in turn causes the effector MAs to become transformed into foam cells. Consistent with this concept, the AEBP1, a transcriptional nuclear repressor with carboxypeptidase activity, has recently been shown to be able to suppress macrophage-cholesterol efflux, via PPAR $\gamma 1$ and $\operatorname{LXR} \alpha$ downregulations, thereby promoting foam cell formation. ${ }^{9}$ However, we could rarely detect AEBP1 protein in foam MAs of human paraffin tissue sections using IHC 

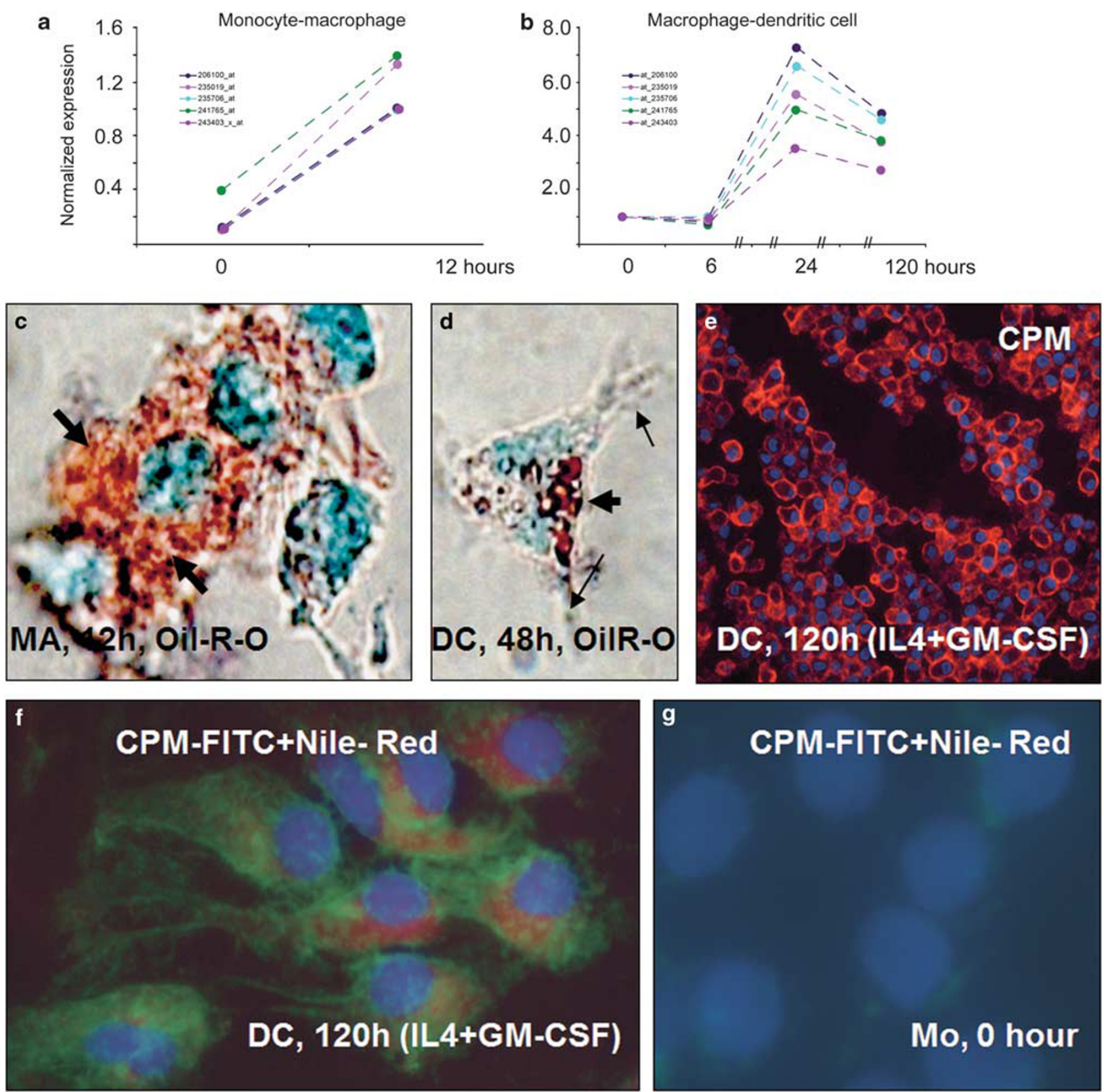

Figure 10 Microarray data for CPM gene activation during monocyte-macrophage (MA) and MA-dendritic cell (DC) differentiations associated with serum lipids and cytokines. ( $\mathbf{a}$ and $\mathbf{b}$ ) Microarray analyses using various probe sets (identified by numbers with different color lines on graphs) show that during monocyte to MA differentiation, there is a robust acute CPM gene activation (a), which is increased further during monocyte-derived MA transition into early DCs induced by interleukin-4 + granulocyte-macrophage-colony-stimulating factor (IL-4 + GM-CSF) (b). (c and d) The lipid (Oil-Red-O) staining of these monolayer cells, viewed under partial phase-contrast lights, revealed remarkable lipid uptake by differentiating MAs (thick arrows of $\mathbf{c}$ ), which appears to be correlated with CPM-gene upregulation. (d) At $48 \mathrm{~h}$ of culture with GM-CSF + IL-4, monocyte-derived differentiating cells having cytoplasmic projections (arrows), a typical dendritic cell morphology, still contain cytoplasmic lipids (thick arrow), albeit in lower quantity compared with cells of image c.

(e) The section of paraffin-embedded cell pellets shows that at the end of differentiation time, CPM-protein expression remains elevated in immature DCs (red fluorescence), which reflects the gene-activating effects of the cytokines applied. (f) The combined fluorescent staining for CPM (green) and Nile-red for neutral lipids (red) simultaneously shows that the lipid content of DCs did not disappear completely by the end of the 5-day culturing time, while CPM-protein is still being expressed, consistent with the gene-expression profile of Figure 10b. (g) Monocytes contain neither lipid nor CPM, as expected. Images of ( $\mathbf{c}$ and $\mathbf{d})$ and $(\mathbf{f}, \mathbf{g})$ are from monolayer cells with $\times 63$ original magnifications. Nuclear counterstaining: methyl-green for panels c and $\mathbf{d}$ and 4'-6-diamidino-2-phenylindole (DAPI) (blue fluorescence) for panels $\mathbf{e}, \mathbf{f}$ and $\mathbf{g}$.

techniques (unpublished data). Nevertheless, based on the cited reference and our present data, the simultaneous presence of the cell membrane-bound CPM and the nuclear
AEBP1 carboxypeptidases appear to have active roles in macrophage lipid regulation, probably via processing peptide(s) that directly or indirectly govern both the lipid 
uptake/influx facilitation (a CPM effect) and the lipid efflux inhibition (an AEBP1 effect), all promoting foam cell formation. In fact, the novel immunohistochemical observation of the selective and inducible expression of CPM-protein in certain macrophages at natural tissue environments reflects functionally distinct subpopulations that are readily detectable with CPM-IHC for diagnostic purposes. On the other hand, the present uncovered lipid metabolism-related features of CPM in differentiating MAs and DCs, which were not previously described, may serve as a new potent proatherogenic-inducible cellular molecule of MAs, which is upregulated by distinct environmental pro-inflammatory cytokines and lipids, but downregulated in mycobacteriuminfected cells and can potentially be targeted. These issues merit further investigation.

Supplementary Information accompanies the paper on the Laboratory Investigation website (http://www.laboratoryinvestigation.org)

\section{ACKNOWLEDGEMENTS}

We thank Maria Besenyei for technical support. This study was supported in part by National Research Funds OTKA K46588 (BD, IM), and TECH-08-A12008-0228 (BD, ZT), OTKA PD101557 (DT) and the University Research Fund for PhD program (IT).

Author contributions: IT performed IHC research and analyses, data collection and wrote the paper; DT, AG, AD, IS and AS performed molecular biology research; GS, ZN, LI, IM and ZT performed research, IHC analyses and data collection; LN designed and directed molecular biology research; and $\mathrm{BD}$ designed the research concept, directed research and wrote the paper.

\section{DISCLOSURE/CONFLICT OF INTEREST}

The authors declare no conflict of interest.

1. Kumar V, Abbas AK, Fausto N, Mitchell RN (eds). Robbins Basic Pathology; Granulomatous Inflammation, pp 56-57; Delayed-Type Hypersensitivity, pp 128-130; Maitra A, Fogo BA. Tuberculosis, pp 516-522, 8th edn. Saunders, Elsevier: Philadelphia, PA, 2007.

2. Asano M, Nakane A, Minagawa T. Endogenous gamma interferon is essential in granuloma formation induced by glycolipid-containing mycolic acid in mice. Infect Immun 1993;61:2872-2878.

3. Ulrichs T, Kaufmann SH. New insights into the function of granulomas in human tuberculosis. J Pathol 2006;208:261-269.

4. Aly $\mathrm{S}$, Laskay $\mathrm{T}$, Mages $\mathrm{J}$, et al. Interferon-gamma-dependent mechanisms of mycobacteria-induced pulmonary immunopathology: the role of angiostasis and CXCR3-targeted chemokines for granuloma necrosis. J Pathol 2007;212:295-305.

5. Nagy B, Soós $G$, Nagy $K$, et al. Natural course of isolated pulmonary Langerhans' cell histiocytosis in a toddler. 3-year follow-up. Respiration 2008;75:215-220.

6. Skidgel RA, Davis RM, Tan F. Human carboxypeptidase M. Purification and characterization of a membrane-bound carboxypeptidase that cleaves peptide hormones. J Biol Chem 1989;264:2236-2241.

7. Skidgel RA, õs EG. Cellular carboxypeptidases. Immunol Rev 1998;161:129-141.

8. Deiteren K, Hendriks D, Scharpe S, et al. Carboxypeptidase M: multiple alliances and unknown partners. Clin Chim Acta 2009; 399:24-39.

9. Majdalawieh A, Zhang L, Fuki IV, et al. Adipocyte enhancer-binding protein 1 is a potential novel atherogenic factor involved in macrophage cholesterol homeostasis and inflammation. Proc Natl Acad Sci USA 2006;103:2346-2351.

10. Fujiwara $\mathrm{H}$, Higuchi $\mathrm{T}$, Sato $\mathrm{Y}$, et al. Regulation of human extravillous trophoblast function by membrane-bound peptidases. Biochim Biophys Acta 2005;1751:26-32.
11. Nagae A, Abe M, Becker RP, et al. High concentration of carboxypeptidase $M$ in lungs: presence of the enzyme in alveolar type I cells. Am J Respir Cell Mol Biol 1993;9:221-229.

12. Tsakiris I, Soos G, Nemes Z, et al. The presence of carboxypeptidase-M in tumour cells signifies epidermal growth factor receptor expression in lung adenocarcinomas: the coexistence predicts a poor prognosis regardless of EGFR levels. J Cancer Res Clin Oncol 2008; 134:439-451.

13. Skidgel RA, McGwire GB, Li XY. Membrane anchoring and release of carboxypeptidase $\mathrm{M}$ : implications for extracellular hydrolysis of peptide hormones. Immunopharmacology 1996;32:48-52.

14. Zhang X, Tan F, Zhang $Y$, et al. Carboxypeptidase $M$ and Kinin B1 receptor interact to facilitate efficient $B 1$ signaling from $B 2$ agonists. J Biol Chem 2008;283:7994-8004.

15. McGwire GB, Skidgel RA. Extracellular conversion of epidermal growth factor (EGF) to des-Arg ${ }^{53}$-EGF by carboxypeptidase M. J Biol Chem 1995;270:17154-17158.

16. Rehli $M$, Krause SW, Kreutz $M$, et al. Carboxypeptidase $M$ is identical to the MAX.1 antigen and its expression is associated with monocyte to macrophage differentiation. J Biol Chem 1995;270: 15644-15649.

17. Krause SW, Rehli M, Andreesen R. Carboxypeptidase $M$ as a marker of macrophage maturation. Immunol Rev 1998;161:119-127.

18. Rehli M, Krause SW, Andreesen R. The membrane-bound ectopeptidase CPM as a marker of macrophage maturation in vitro and in vivo. Adv Exp Med Biol 2000;477:205-216.

19. Ridley DS, Ridley MJ. Rationale for the histological spectrum of tuberculosis. A basis for classification. Pathology 1987;19:186-192.

20. Cardona PJ, Llatjos R, Gordillo $S$, et al. Evolution of granulomas in lungs of mice infected aerogenically with Mycobacterium tuberculosis. Scan J Immunol 2000;52:156-163.

21. Muller $\mathrm{H}$, Kruger $\mathrm{S}$. Immunohistochemical analysis of cell composition and in situ cytokine expression in HIV and non-HIV-associated tuberculous lymphadenitis. Immunobiology 1994;191:354-368.

22. Matsuura F, Yamashita S, Hirano K, et al. Activation of monocytes in vivo causes intracellular accumulation of lipoprotein-derived lipids and marked hypocholesterolemia-a possible pathogenesis of necrobiotic xanthogranuloma. Atherosclerosis 1999;142:355-365.

23. Szeliga J, Daniel DS, Yang $\mathrm{CH}$, et al. Granulocyte-macrophage colony stimulating factor-mediated innate responses in tuberculosis. Tuberculosis 2008;88:7-20.

24. Douda DN, Famakovski N, Dell S, et al. SP-D counteracts GM-CSFmediated increase of granuloma formation by alveolar macrophages in lysinuric protein intolerance. Orphanet J Rare Dis 2009;4:29.

25. Ma Y, Gal A, Koss MN. The pathology of pulmonary sarcoidosis: update. Semin Diagn Pathol 2007:24:150-161.

26. Okabe T. Origin of epithelioid cells in sarcoid granuloma. Nippon Rinsho 2002;60:1714-1719.

27. Dezso B, Haas PG, Hamzavi F, et al. The mechanism of local tumor irradiation combined with interleukin 2 therapy in murine renal carcinoma: histological evaluation of pulmonary metastases. Clin Cancer Res 1996;2:1543-1552.

28. Gogolak P, Rethi B, Szatmari I, et al. Differentiation of CD1a- and CD1a+ monocyte-derived dendritic cells is biased by lipid environment and PPARgamma. Blood 2007;109:643-652.

29. Szanto A, Balint LB, Nagy ZS, et al. STAT6 transcription factor is a facilitator of the nuclear receptor PPAR $\gamma$-regulated gene expression in macrophages and dendritic cells. Immunity 2010;33:699-712.

30. Szatmari I, Goolak P, Im JS, et al. Activation of PPARgamma specifies a dendritic cell subtype capable of enhanced induction of iNKT cell expansion. Immunity 2004;21:95-106.

31. Gustafsson C, Mjösberg J, Matussek A, et al. Gene expression profiling of human decidual macrophages: evidence for immunosuppressive phenotype. PLoS One 2008;3:e2078.

32. Szanto A, Benko S, Szatmari I, et al. Transcriptional regulation of human CYP27 integrates retinoid, peroxisome proliferator-activated receptor, and liver $\mathrm{X}$ receptor signaling in macrophages. Mol Cell Biol 2004;24:8154-8166.

33. Szatmari I, Torocsik D, Agostini M, et al. PPARg regulates the function of human dendritic cells primarily by altering lipid metabolism. Blood 2007;110:3271-3280.

34. Almeida PE, Silva AR, Maya-Monteiro CM, et al. Mycobacterium bovis bacillus Calmette-Guérin infection induces TLR2-dependent 
peroxisome proliferator-activated receptor gamma expression and activation: functions in inflammation, lipid metabolism, and pathogenesis. J Immunol 2009;183:1337-1345.

35. Greenspan P, Mayer EP, Fowler SD. Nile red: a selective fluorescent stain for intracellular lipid droplets. J Cell Biol 1985;100: 965-973.

36. Szatmari I, Pap A, Ruhl R, et al. PPARgamma controls CD1d expression by turning on retionic acid synthesis in developing human dendritis cells. J Exp Med 2006:203:2351-2362.

37. Torocsik $D$, Barath $M$, Benko $S$, et al. Activation of liver $X$ receptor sensitizes human dendritic cells to inflammatory stimuli. J Immunol 2010;184:5456-5465.

38. Marton IJ, Dezso B, Radics T, et al. Distribution of interleukin-2 receptor alpha-chain and cells expressing major histocompatibility complex class II antigen in chronic human periapical lesions. Oral Microbiol Immunol 1998;13:259-262.

39. Clemens DL, Horwitz MA. Characterisation of the Mycobacterium tuberculosis phagosome and evidence that phagosomal maturation is inhibited. J Exp Med 1995;181:257-270.

40. Fulton SA, Reba SM, Pai RK, et al. Inhibition of major histocompatibility complex II expression and antigen processing in murine alveolar macrophages by Mycobacterium bovis BCG and 19-kiloDalton mycobacterial lipoprotein. Infect Immun 2004;72:2101-2110.

41. Latchumanan VK, Balkhi MY, Sinha A, et al. Regulation of immune responses to Mycobacterium tuberculosis secretory antigens by dendritic cells. Tuberculosis 2005;85:377-383.

42. Yamauchi A, Dai S-Y, Nakagawa R, et al. Galectin-9 induces maturation of human monocyte-derived dendritic cells. Jpn J Clin Immunol 2005;28:381-388.

43. Beutler E, Grabowski GA. Gaucher disease. In: Scriver CR, Beaudet AL, Sly WS, Valle D (eds). The Metabolic and Molecular Basis of Inherited Disease, Vol. III, 8th edn. McGraw-Hill: New York, 2001, pp 3635-3668.
44. Boven LA, van Meurs M, Boot RG, et al. Gaucher cells demonstrate a distinct macrophage phenotype and resemble alternatively activated macrophages. Am J Clin Pathol 2004;122:359-369.

45. Tontonoz P, Nagy L, Alvarez JG, et al. PPARgamma promotes monocyte/macrophage differentiation and uptake of oxidized LDL. Cell 1998;93:241-252.

46. Dushkin $\mathrm{Ml}$, Khoshenko OM, Posokhova EN, et al. Agonist of PPARalpha, PPAR-gamma and inhibits the formation of foam cells from macrophages in mice with inflammation. Bull Exp Biol Med 2007;144: 713-716.

47. Rees AJ. Monocyte and macrophage biology: an overview. Semin Nephrol 2010;30:216-233.

48. Qian B-Z, Pollard JW. Macrophage diversity enhances tumor progression and metastasis. Cell 2010;141:39-51.

49. Marquez-Curtis $L$, Jalili $A$, Deiteren $K$, et al. Carboxypeptidase $M$ expressed by human bone marrow cells cleaves the C-terminal lysine of SDF-1[alpha]: another player in hematopoietic stem/progenitor cell mobilization? Stem Cells 2008:26:1211-1220.

50. Paulson KE, Zhu $S$, Chen $M$, et al. Resident intimal dendritic cells accumulate lipid and contribute to the initiation of atherosclerosis. Circ Res 2010;106:383-390.

51. Klos A, Tenner AJ, Johswich KO, et al. The role of the anaphylatoxins in health and disease. Mol Immunol 2009;46:2753-2766.

52. Mount PF, Lane N, Venkatesan S, et al. Bradykinin stimulate endothelial cell fatty acid oxidation by CaMKK-dependent activation of AMPK. Atherosclerosis 2008;200:28-36.

This work is licensed under the Creative Commons Attribution-NonCommercial-No Derivative Works 3.0 Unported License. To view a copy of this license, visit http:// creativecommons.org/licenses/by-nc-nd/3.0/ 